\title{
Electrically Conducting n-type AlGaN/GaN Distributed Bragg Reflectors Grown by Metalorganic Chemical Vapor Deposition
}

Yuh-Shiuan Liu, ${ }^{1}$ A F M Saniul Haq, ${ }^{1}$ Tsung-Ting Kao, ${ }^{1}$ Karan Mehta, ${ }^{1}$ Shyh-Chiang Shen, ${ }^{1}$

Theeradetch Detchprohm, ${ }^{1}$ P. Douglas Yoder, ${ }^{1}$ Russell D. Dupuis, ${ }^{1, a, b)}$ Hongen Xie, ${ }^{2}$ and

Fernando A. Ponce ${ }^{2}$

${ }^{1}$ Center for Compound Semiconductors, School of Electrical and Computer Engineering, Georgia Institute of Technology, 777 Atlantic Dr. NW, Atlanta, Georgia 30332-0250, USA

${ }^{2}$ Department of Physics, Arizona State University, Tempe, Arizona 85287-1504

Abstract

We report an electrically conducting 40-pair silicon doped $\mathrm{Al}_{0.12} \mathrm{Ga}_{0.88} \mathrm{~N} / \mathrm{GaN}$ distributed Bragg reflector (DBR) grown by metalorganic chemical vapor deposition on a silicon doped $n$-type GaN template. Due to the relatively small lattice mismatch between $\mathrm{AlGaN}$ and GaN, strain managing layers are not required for crack-free $n$-DBR growth. The DBR demonstrates a peak reflectivity of $91.6 \%$ at $368 \mathrm{~nm}$ with stopband of $11 \mathrm{~nm}$. In addition, the 40-pair $n$ DBR shows the vertical resistance of $5.5 \Omega$, which corresponds to bulk resistivity of $0.52 \Omega$ $\mathrm{cm}$, near the maximum measured current of $100 \mathrm{~mA}$. 


\section{Keywords:}
A3. Metalorganic chemical vapor deposition
B1. Nitride
B2. Semiconductor III-V material
B3. Laser diodes

\section{PACS \#:}

42.55.Px Semiconductor lasers, solid-state lasers

78.66.Fd Optical properties of specific thin films, III-V semiconductors

81.15.Gh Methods of deposition of films and coatings; film growth and epitaxy, Chemical vapor deposition including plasma-enhanced CVD, MOCVD, etc.

\footnotetext{
a) Also with School of Materials Science and Engineering, Georgia Institute of Technology

b) Authors to whom correspondence should be addressed;

Electronic mail: dupuis@gatech.edu
} 


\section{Introduction}

Vertical-cavity surface-emitting lasers (VCSELs) have numerous applications including, optical fiber data transmission [1-3], optically pumped solid-state lasers [4-6], and chip-scale atomic clocks [7-10]. The key to fabricate a conventional current-injection VCSEL largely depends on the crystal quality of distributed Bragg reflectors (DBRs) composed of epitaxially grown semiconductor materials [11]. For III-nitride material system, the growth of highreflectivity DBR structures is extremely challenging due to the large lattice mismatch between $\mathrm{GaN}$ and $\mathrm{AlN}$ as well as the relatively low refractive index contrast of this material system. To mitigate the tensile strain originating from lattice mismatch, Waldrip, et al. [12] and Huang, et al. [13] reported the tensile strain can be compensated by inserted AlN interlayers or an GaN/AlN superlattice, respectively. Aside from strain-engineering AlGaN-based DBRs, Carlin, et al. [14] employed an AlInN ternary alloy, latticed matched to GaN, for InAlN/GaN DBR growth. Other epitaxial DBR approaches included introducing boron ternary alloy $[15,16]$ as well as forming air gaps between nitride materials $[17,18]$. Despite the great progress on developing nitride DBRs, the majority of structures demonstrated to date limit the possibility for electrical conduction due to wide-bandgap nature of $\mathrm{AlN}$ as well as the potential barriers forming from band offsets between DBR layers. Without an electrically conducting DBR structure, lateral contacts are required, which inevitably reduces the number of devices per wafer as well as increasing fabrication complexity. Unlike the majority of $\mathrm{AlGaN} / \mathrm{GaN}$ heterostructures where the structure thickness is significantly shorter than coherence length of electron, the total epitaxial thickness of $n$-DBR significantly exceed the coherent length of electron resulting in difficulties in realizing the electrically conducting $n$-DBR. To the best of our knowledge, Arita, et al. [19] is the only research team which has reported an electrically conducting III-N DBR; however, this 
paper only describes the ability to pass current without any further characterization. As a result, a detailed characterization study for an electrically conducting $n$-DBR was- carried out in this work.

\section{Experimental Procedure}

In this work, we report an electrically conducting $n$-type DBR consisting of a silicondoped 40-pair $\mathrm{Al}_{0.12} \mathrm{GaN}_{0.88} \mathrm{~N} / \mathrm{GaN}$ DBR heterostructure with the thicknesses of each layer as quarter optical wavelength thick. The epitaxial growth was performed in a Thomas-Swan (now AIXTRON) $6 \times 2 "$ close-coupled showerhead metalorganic chemical vapor deposition (MOCVD) reactor system. Trimethylaluminum $\left(\mathrm{Al}\left(\mathrm{CH}_{3}\right)_{3}, \mathrm{TMAl}\right)$ and trimethylgallium $\left(\mathrm{Ga}\left(\mathrm{CH}_{3}\right)_{3}, \mathrm{TMGa}\right)$ were used for group III precursors while ammonia $\left(\mathrm{NH}_{3}\right)$ was used for group V precursor. To obtain $n$-type electrical conduction properties, silane $\left(\mathrm{SiH}_{4}\right)$ was used as $n$-type dopant source. The average growth rate for this 40 -pair $n$-DBR is about $0.8 \mu \mathrm{m} / \mathrm{hr}$ and the growth was performed on a $\sim 3.5 \mu \mathrm{m}$ silicon-doped GaN template grown on a (0001) sapphire substrate in a $\mathrm{H}_{2}$ ambient with the growth pressure and temperature of 200 Torr and $\sim 1060{ }^{\circ} \mathrm{C}$, respectively. The free-carrier concentration for the $n$-GaN template was estimated to be $4 \times 10^{18} \mathrm{~cm}^{-3}$ and $1 \times 10^{18} \mathrm{~cm}^{-3}$ for each layer in the $n$-DBR structure. To study the electrical properties of the DBR, a $\sim 3 \mu \mathrm{m}$ deep mesa was created to expose the $n$-GaN layer below the DBR using inductivelycoupled plasma reactive-ion etching (ICP-RIE). After the mesa etching, the exposed mesa surface is treated in a diluted $\mathrm{KOH}-$ based solution under ultraviolet light illumination to remove the dry-etching-induced surface damage. Finally, $n$-type ohmic contacts with a $60 \mu \mathrm{m}$ diameter circular mesa geometry were deposited on top of the mesa and the bottom of the etched access trench followed by a thermal annealing performed in $\mathrm{N}_{2}$ ambient.

\section{Results and Discussion}


Figure 1 shows the reflectivity spectra measured at 300K by a Shimadzu UV2401PC ultraviolet-visible spectrometer for a 40 -pair $\mathrm{Al}_{0.12} \mathrm{Ga}_{0.88} \mathrm{~N} / \mathrm{GaN} n$-DBR structure grown on an $n$ type silicon-doped GaN template. The spectrometer is equipped with halogen and deuterium lamps for visible and ultraviolet wavelength measurements, respectively. In this study, the halogen lamp was used for obtaining reflectivity above $283 \mathrm{~nm}$ while the deuterium lamp was used for the reflectivity between 200 to $283 \mathrm{~nm}$ and the measurement step was $0.5 \mathrm{~nm}$. Although GaN:Si has a finite absorption around $368 \mathrm{~nm}$ due to excitonic absorption near the material bandgap energy [20], the measured silicon-doped $\mathrm{Al}_{0.12} \mathrm{Ga}_{0.88} \mathrm{~N} / \mathrm{GaN}$ DBR still demonstrated a peak reflectivity of $91.6 \%$ at $368 \mathrm{~nm}$ with a stopband of $11 \mathrm{~nm}$. As a comparison, the ideal reflectivity spectrum, obtained via a numerical method, is also shown in Fig. 1 and a peak reflectivity of $97.2 \%$ can be achieved. The nature of such narrow stopband originates from the relatively small refractive index contrast between $\mathrm{Al}_{0.12} \mathrm{Ga}_{0.88} \mathrm{~N}: \mathrm{Si}$ and $\mathrm{GaN}: \mathrm{Si}$. To increase the stopband bandwidth, an $\mathrm{Al}_{\mathrm{x}} \mathrm{Ga}_{1-\mathrm{x}} \mathrm{N}: \mathrm{Si}$ layer with larger aluminum mole fraction is required; however, increasing the $\mathrm{Al}$ mole fraction will create a larger electrical resistance through the $n$ DBR structure due to the larger potential barrier at the silicon-doped $\mathrm{Al}_{\mathrm{x}} \mathrm{Ga}_{1-\mathrm{x}} \mathrm{N} / \mathrm{GaN}$ interfaces resulting from an increased conduction-band offset. In addition to the limitation of carrier transport through potential barriers, higher aluminum mole fraction $\mathrm{Al}_{\mathrm{x}} \mathrm{Ga}_{1-\mathrm{x}} \mathrm{N}$ :Si materials will experience even larger tensile strain, which usually induce defects formation and potentially cracks.

To achieve a high reflectivity with relatively small refractive index contrast between $\mathrm{Al}_{0.12} \mathrm{Ga}_{0.88} \mathrm{~N}: \mathrm{Si}$ and $\mathrm{GaN}: \mathrm{Si}$, a mirror like surface is required to reduce surface scattering. In addition, smooth surface formation is required for a high-quality active region growth on top of the $n$-DBR structure for VCSELs or microcavity light-emitting diodes (MCLEDs). Illustrated in 
Fig. 2 is the surface morphology of a 40 -pair $\mathrm{Al}_{0.12} \mathrm{Ga}_{0.88} \mathrm{~N} / \mathrm{GaN} n$-DBR grown on (0001) sapphire measured by atomic force microscopy (AFM). Even with $n$-type silicon doping and the tensile strain in $\mathrm{Al}_{0.12} \mathrm{Ga}_{0.88} \mathrm{~N}$, smooth surface formation with terraced step-flow, characteristic of two-dimensional (2D) layer-by-layer III-nitride epitaxial growth, is observed. The root-meansquare roughness is $0.11 \mathrm{~nm}, 0.38 \mathrm{~nm}, 1.19 \mathrm{~nm}$ for $1 \times 1 \mu \mathrm{m}^{2}, 5 \times 5 \mu \mathrm{m}^{2}$, and $20 \times 20 \mu \mathrm{m}^{2}$ measurements, respectively.

Illustrated in Fig. 3 are the current-voltage (I-V) characteristics of the $n$-DBR measured at room temperature under $\mathrm{DC}$ conditions. The measurement was terminated at the maximum measured current of $100 \mathrm{~mA}(\sim 7.7 \mathrm{~V})$ and non-linear I-V characteristics were observed, which may be attributed to the inhomogeneous pile-up of charge under bias and subsequently affects the internal electrical field profile. By taking the differential of the I-V curve, the series resistance of $17.7 \Omega$ can be determined near the maximum measured current of $100 \mathrm{~mA}$. The measured series resistance is the combination of two metal contacts resistances, the vertical resistance through the $n$-DBR, and the lateral resistance on the bottom of mesa for the lateral device in this work. To extract each of the resistances from the measured series resistance, 4point probe measurement were performed on top and bottom of mesa to study contacts resistances and the sheet resistances of the material. The measurement shows the resistance contributed from top and bottom contacts were 7.3 and $3.6 \Omega$, respectively, while the lateral resistance on the bottom of the mesa contributed additional $1.3 \Omega$. By subtracting contacts and lateral resistances from series resistance, the vertical resistance through the $n$-DBR structure can be determined as $5.5 \Omega$, which corresponds to an overall bulk resistivity of $0.52 \Omega-\mathrm{cm}$.

Cross-section samples of the 40-pair $n$-DBR were prepared for transmission electron microscopy (TEM) measurement using mechanical polishing and focused Ga ion beam (FIB) to 
form uniform thickness across the entire $n$-DBR structure. Figure 4 is a large-magnification cross-section image of portion of the 40-pair $n$-DBR, taken under bright-field conditions with $\mathrm{g}=$ 0002. Abrupt and perfectly flat interfaces between $\mathrm{GaN}: \mathrm{Si}$ and $\mathrm{Al}_{0.12} \mathrm{Ga}_{0.88} \mathrm{~N}: \mathrm{Si}$ are clearly shown with distinctive contrasts. The brighter layers correspond to $\mathrm{Al}_{0.12} \mathrm{Ga}_{0.88} \mathrm{~N}: \mathrm{Si}$ while the darker layers correspond to GaN:Si. The observed flat interfaces are important to improve the optical reflectivity by reducing interface roughness scattering. Furthermore, the flat interfaces and the smooth surfaces (the RMS roughness for a $20 \times 20 \mu \mathrm{m}^{2}$ scan is $1.19 \mathrm{~nm}$ ) described in Fig.2 are important indications that the entire $n$-DBR structure was grown in the Frank-van der Merwe (layer-by-layer) mode as the interfaces observed in the middle of structure and the finishing surface demonstrated comparable morphology. From these images, accurate values of the thicknesses of the GaN:Si and $\mathrm{Al}_{0.12} \mathrm{Ga}_{0.88} \mathrm{~N}$ :Si layers can be determined. The TEM thickness measurements agree very well with the nominal growth thickness values. The observed thicknesses deviations, which was determined to be less than $3 \%$ for both $\mathrm{GaN}$ and $\mathrm{Al}_{0.12} \mathrm{Ga}_{0.88} \mathrm{~N}$ layers, from calibrated growth using high-resolution triple-axis X-ray diffractometer can originate from run-to-run variations, wafer uniformity, and progressively slow changing in growth chamber condition throughout the growth run.

\section{Conclusion}

In summary, we report an $n$-type electrically conducting DBR using 40-pair silicon doped $\mathrm{Al}_{0.12} \mathrm{Ga}_{0.88} \mathrm{~N} / \mathrm{GaN}$ DBR structure grown by MOCVD. The DBR structure exhibits a peak reflectivity of $91.6 \%$ at $368 \mathrm{~nm}$ with a $\sim 11 \mathrm{~nm}$ stopband. A high crystalline quality was verified by AFM and TEM imaging techniques. By performing a mesa-etching and metal-contact formation on this $\mathrm{n}-\mathrm{Al}_{01.2} \mathrm{Ga}_{0.88} \mathrm{~N}-\mathrm{GaN}$ DBR structure, we determined that this $n$-DBR has a vertical electrical resistance of $5.5 \Omega$, which corresponds to bulk resistivity of $0.52 \Omega$-cm, near 
the maximum measured current of $100 \mathrm{~mA}$.

\section{Acknowledgements}

This work is supported by the Defense Advanced Research Projects Agency under Contract \# W911NF-15-1-0026. RDD acknowledges additional support of the Steve W. Chaddick Endowed Chair in Electro-Optics and the Georgia Research Alliance. 


\section{References}

[1] T.B. Gibbon, K. Prince, T.T. Pham, A. Tatarczak, C. Neumeyr, E. Rönneberg, M. Ortsiefer, I. T. Monroy, VCSEL transmission at $10 \mathrm{~Gb} / \mathrm{s}$ for $20 \mathrm{~km}$ single mode fiber WDM-PON without dis persion compensation or injection locking, Optical Fiber Technology, 17 (2011) 41-45.

[2] P. Moser, J.A. Lott, P. Wolf, G. Larisch, A. Payusov, N.N. Ledentsov, W. Hofmann, D. Bimbe rg, 99 fJ/(bit-km) Energy to Data-Distance Ratio at 17 Gb/s Across 1 km of Multimode Optical F iber With 850-nm Single-Mode VCSELs, Photonics Technology Letters, IEEE, 24 (2012) 19-21.

[3] P. Schnitzer, M. Grabherr, R. Jager, F. Mederer, R. Michalzik, D. Wiedenmann, K.J. Ebeling, GaAs VCSEL's at $\lambda=780$ and $835 \mathrm{~nm}$ for short-distance $2.5-\mathrm{Gb} / \mathrm{s}$ plastic optical fiber data links, Photonics Technology Letters, IEEE, 11 (1999) 767-769.

[4] R. Zhou, E. Li, H. Li, P. Wang, J. Yao, Continuous-wave, 15.2 W diode-end-pumped Nd:YA G laser operating at 946 nm, Optics Letters, 31 (2006) 1869-1871.

[5] L. Goldberg, C. McIntosh, B. Cole, VCSEL end-pumped passively Q-switched Nd:YAG laser with adjustable pulse energy, Optics Express, 19 (2011) 4261-4267.

[6] Y.P. Lan, C. Yung-Fu, K.F. Huang, H.C. Lai, J.S. Pan, Oxide-confined vertical-cavity surfaceemitting laser pumped Nd:YVO $<$ sub $>4</$ sub $>$ microchip lasers, Photonics Technology Letters, I EEE, 14 (2002) 272-274.

[7] M.J. Mescher, R. Lutwak, M. Varghese, An ultra-low-power physics package for a chip-scale 
atomic clock, in: Solid-State Sensors, Actuators and Microsystems, 2005. Digest of Technical Pa pers. TRANSDUCERS '05. The 13th International Conference on, 2005, pp. 311-316 Vol. 311. [8] S. Knappe, P. Schwindt, V. Shah, L. Hollberg, J. Kitching, L. Liew, J. Moreland, A chip-scale atomic clock based on 87Rb with improved frequency stability, Optics Express, 13 (2005) 12491253.

[9] R. Lutwak, P. Vlitas, M. Varghese, M. Mescher, D.K. Serkland, G.M. Peake, The MAC - a mi niature atomic clock, in: Frequency Control Symposium and Exposition, 2005. Proceedings of $\mathrm{t}$ he 2005 IEEE International, 2005, pp. 6 pp.

[10] D.K. Serkland, G.M. Peake, K.M. Geib, R. Lutwak, R.M. Garvey, M. Varghese, M. Mescher, VCSELs for atomic clocks, in, Proc. SPIE, 2006, pp. 613208-613208-613211.

[11] R.D. Dupuis, P.D. Dapkus, Room-temperature operation of distributed-Bragg-confinement $\mathrm{Ga}_{1-\mathrm{x}} \mathrm{Al}_{\mathrm{x}} \mathrm{As}-\mathrm{GaAs}$ lasers grown by metalorganic chemical vapor deposition, Applied Physics Lett ers, 33 (1978) 68-69.

[12] K.E. Waldrip, J. Han, J.J. Figiel, H. Zhou, E. Makarona, A.V. Nurmikko, Stress engineering during metalorganic chemical vapor deposition of $\mathrm{AlGaN} / \mathrm{GaN}$ distributed Bragg reflectors, Appl ied Physics Letters, 78 (2001) 3205-3207.

[13] G.S. Huang, T.C. Lu, H.H. Yao, H.C. Kuo, S.C. Wang, C.-W. Lin, L. Chang, Crack-free Ga $\mathrm{N} / \mathrm{AlN}$ distributed Bragg reflectors incorporated with GaN / AlN superlattices grown by metal 
organic chemical vapor deposition, Applied Physics Letters, 88 (2006) 061904.

[14] J.-F. Carlin, J. Dorsaz, E. Feltin, R. Butté, N. Grandjean, M. Ilegems, M. Laügt, Crack-free f ully epitaxial nitride microcavity using highly reflective AlInN / GaN Bragg mirrors, Applied Ph ysics Letters, 86 (2005) 031107.

[15] M. Abid, T. Moudakir, Z. Djebbour, G. Orsal, S. Gautier, A. En Naciri, A. Migan-Dubois, A. Ougazzaden, Blue-violet boron-based Distributed Bragg Reflectors for VCSEL application, Jou rnal of Crystal Growth, 315 (2011) 283-287.

[16] M. Abid, T. Moudakir, G. Orsal, S. Gautier, A. En Naciri, Z. Djebbour, J.-H. Ryou, G. Patria rche, L. Largeau, H.J. Kim, Z. Lochner, K. Pantzas, D. Alamarguy, F. Jomard, R.D. Dupuis, J.-P. Salvestrini, P.L. Voss, A. Ougazzaden, Distributed Bragg reflectors based on diluted boron-based BAlN alloys for deep ultraviolet optoelectronic applications, Applied Physics Letters, 100 (2012) 051101.

[17] T. Mitsunari, T. Tanikawa, Y. Honda, M. Yamaguchi, H. Amano, AlN/air distributed Bragg r eflector by GaN sublimation from microcracks of AlN, Journal of Crystal Growth, 370 (2013) 16 $-21$.

[18] D. Chen, J. Han, High reflectance membrane-based distributed Bragg reflectors for GaN ph otonics, Applied Physics Letters, 101 (2012) 221104.

[19] M. Arita, M. Nishioka, Y. Arakawa, InGaN Vertical Microcavity LEDs with a Si-Doped AlG 
aN/GaN Distributed Bragg Reflector, physica status solidi (a), 194 (2002) 403-406.

[20] J.F. Muth, J.H. Lee, I.K. Shmagin, R.M. Kolbas, H.C. Casey, B.P. Keller, U.K. Mishra, S.P.

DenBaars, Absorption coefficient, energy gap, exciton binding energy, and recombination lifetim e of GaN obtained from transmission measurements, Applied Physics Letters, 71 (1997) 2572-25

74. 


\section{Figure Captions}

Fig. 1. Reflectivity spectra for measured (blue-solid curve) and simulated (red-circled curve) 40-pair silicon doped $\mathrm{Al}_{0.12} \mathrm{Ga}_{0.88} \mathrm{~N} / \mathrm{GaN}$ DBR structure on silicon doped $n$-GaN template.

Fig. 2. (Color online) Atomic-force microscopy measurements of the 40-pair silicon doped $\mathrm{Al}_{0.12} \mathrm{Ga}_{0.88} \mathrm{~N} / \mathrm{GaN}$ DBR structure on silicon doped $n$-GaN template taken at $1 \times 1 \mu \mathrm{m}^{2}$, $5 \times 5 \mu \mathrm{m}^{2}$, and $20 \times 20 \mu \mathrm{m}^{2}$ and the corresponding root-mean-square roughness is 0.11 $\mathrm{nm}, 0.38 \mathrm{~nm}, 1.19 \mathrm{~nm}$, respectively.

Fig. 3. Current-voltage (I-V) characteristic of the 40-pair silicon doped $\mathrm{Al}_{0.12} \mathrm{Ga}_{0.88} \mathrm{~N} / \mathrm{GaN}$ DBR structure on silicon doped $n$-GaN template under a DC measurement condition at room temperature. The series resistance was determined to be $17.7 \Omega$ near the maximum measured current of $100 \mathrm{~mA}$.

Fig. 4. Large-magnification cross-section image of portion of the 40-pair silicon-doped $\mathrm{Al}_{0.12} \mathrm{Ga}_{0.88} \mathrm{~N} / \mathrm{GaN}$ DBR structure. This transmission electron microscopy bright-field image was taken with $g=0002$. The brighter layers correspond to $\mathrm{Al}_{0.12} \mathrm{Ga}_{0.88} \mathrm{~N}: \mathrm{Si}$ while the darker layers correspond to GaN:Si. The speckles were originated from the surface damage caused by FIB process during sample preparation. 


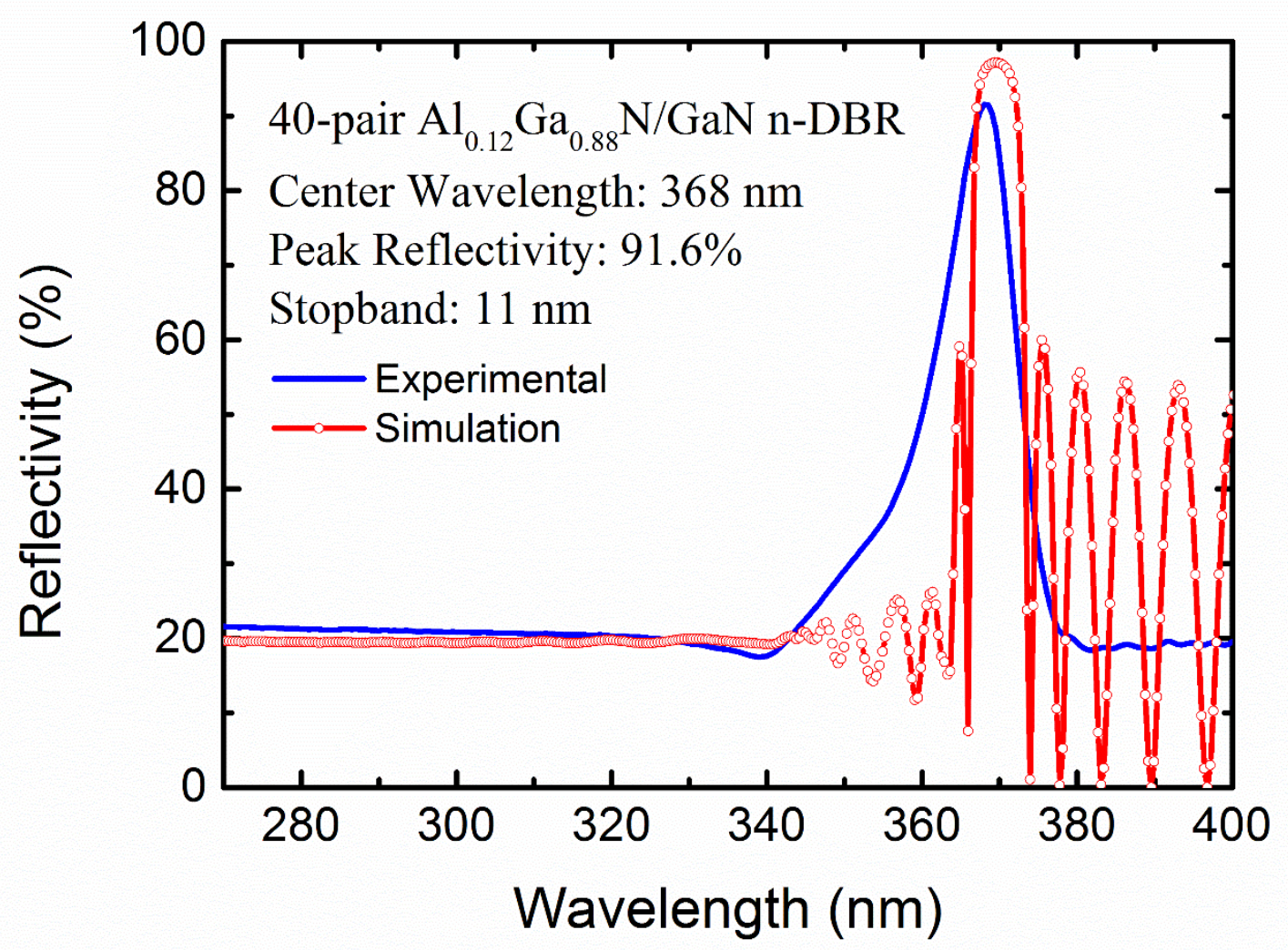

Fig. 1 of 4, Liu, et al. 

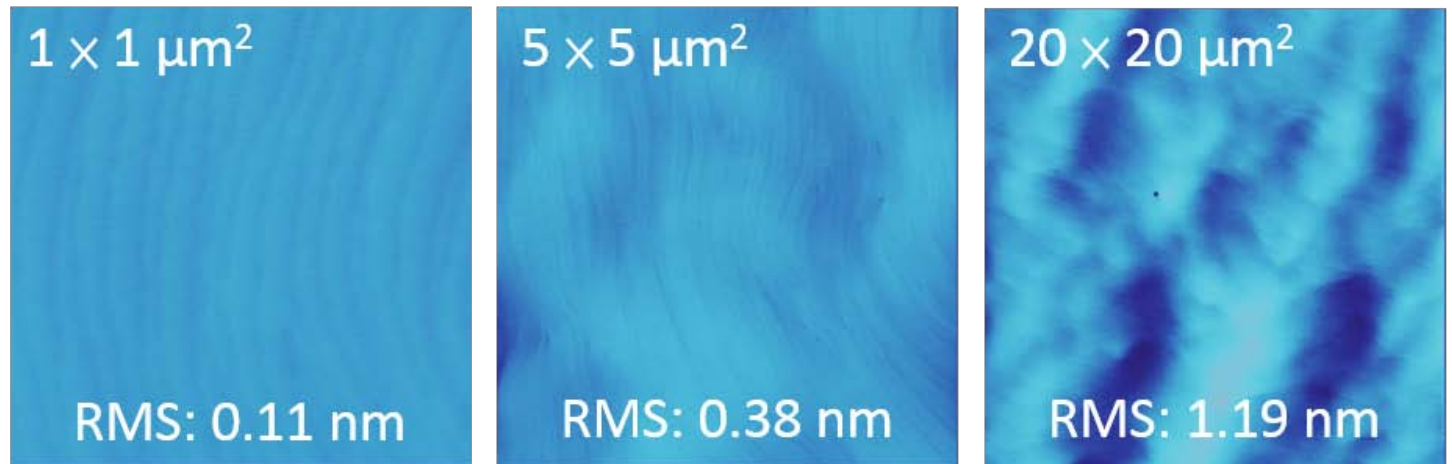

$15 \mathrm{~nm}$

Fig. 2 of 4, Liu, et al. 


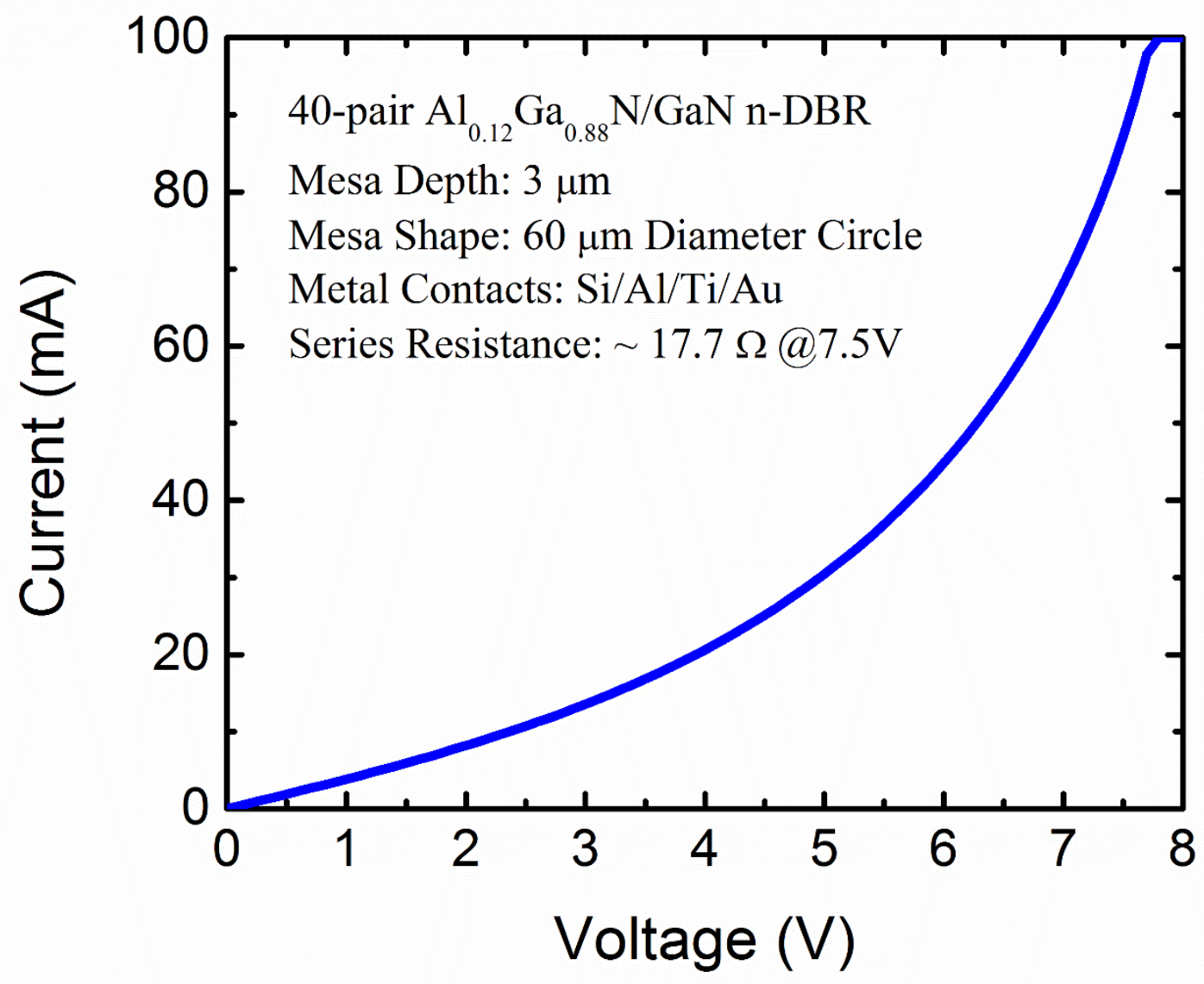

Fig. 3 of 4, Liu, et al. 


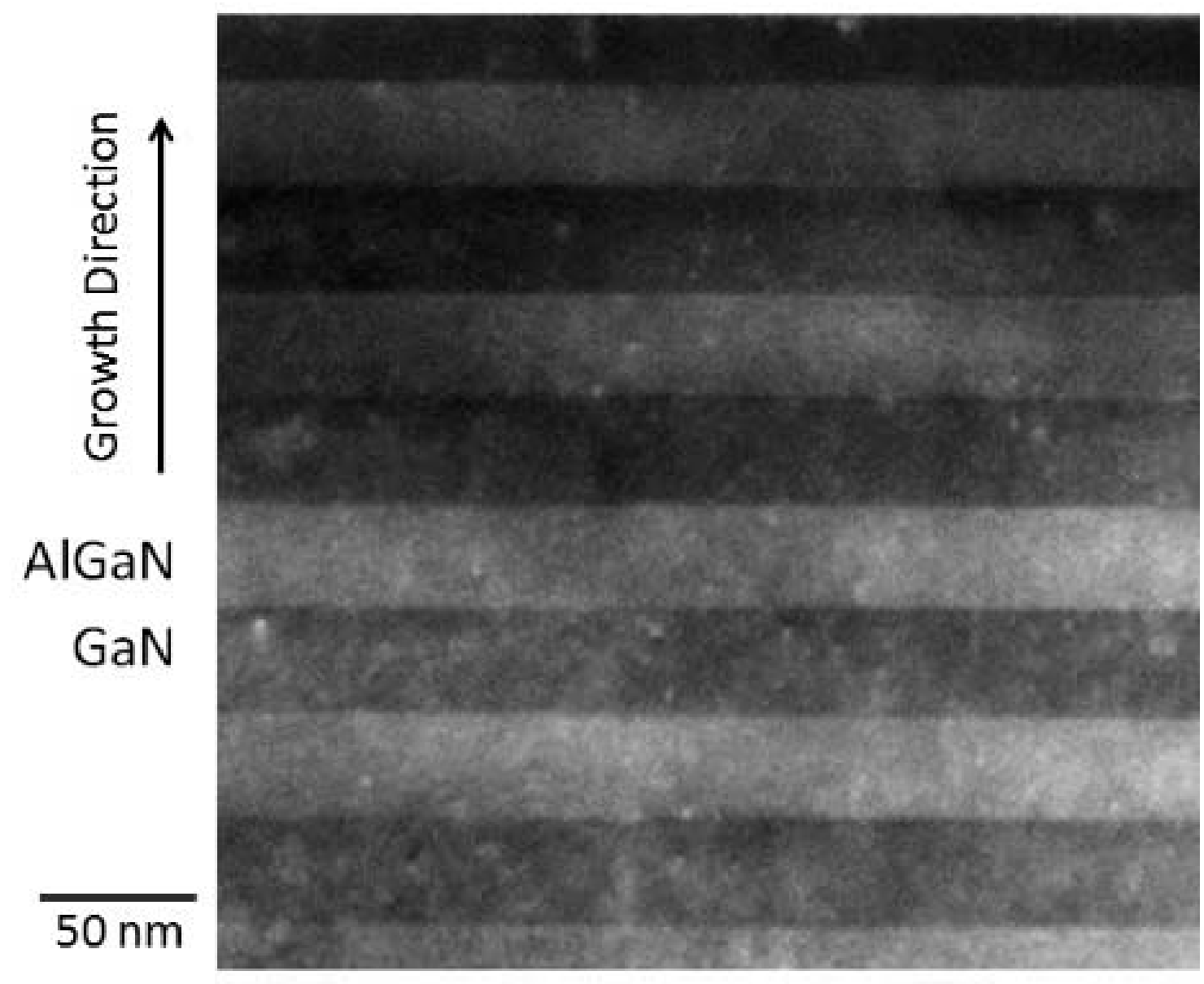

Fig. 4 of 4, Liu, et al. 